\title{
An Impact Study on Training Programme on Integrated Pest Management
}

\author{
Gurram Ranjitha*, Jillela Teza and A. Veeraiah \\ Krishi Vigyan Kendra, Utukur, Kadapa, Andhra Pradesh - 516003, India \\ *Corresponding author
}

\begin{tabular}{|l|}
\hline K e y w o r d s \\
KVK, IPM, Pesticide, \\
Training, Adoption, \\
Knowledge, \\
Evaluation
\end{tabular}

\section{A B S T R A C T}

In modern agriculture, in view of the rapid progress in newer techniques of cultivation and availability of several options of crop management practices, reliance exclusively on chemical control for insect pest management has not yielded desired returns for the farmer. Integrated pest Management (IPM) became an effective alternative to the use of chemicals. Hence, imparting knowledge on modern technologies to the farmers has become one of the most important mandate of the extension system of India. Capacity building of farmers to update their knowledge and skills in modern agriculture technologies is one of the mandate of KVKs The present study was conducted on evaluating the effectiveness of farmers trainings on Integrated Pest Management (IPM) held at Krishi Vigyan Kendra (KVK), Utukur conducted which is needed for further improvement in their standard. Two variables namely, respondents socio economic status and their knowledge levels about the IPM practices learned in training programme at KVK Utukur were measured by a structured interview schedule to study outcome of the training. The impact was evaluated by knowing the adoption status of IPM practices by the trainees, the problems faced by them in adoption of these practice. A typical trainee was old aged (> 50 years) married male with education level of being illiterate to primary educated, from rural and agricultural background and had a gross monthly income of less than Rs 10,000. Post evaluation scores of gain in overall knowledge about various practices indicate 70-95\% improvement in their knowledge. All the trainees had positive change in the level of knowledge after the training. Adoption status of IPM practices was studied to know the impact of training programmes. It is indicated that 85.8 percent of the trainees had adopted IPM (52.8\% continued and $33 \%$ discontinued) where as 13.2 percent did not adopt. It can be observed that various problems faced by farmers were labour work load in sowing intercrop, non-availability of pheromone traps, non-availability of neem oil and Bacillus thuringiensis $(\mathrm{Bt})$ in pesticide shops, fear of increase in pest population if not sprayed of which majority fear of increase in pest population if not sprayed regularly. We conclude that further promotion on IPM adoption is required to minimize utilization of pesticide and attaining sustainable agricultural production.

\section{Introduction}

With deforestation, humans alternated the pest habitats and started habituating the forests lands and farming areas and thus exotic pests were introduced to areas where it is not generally noticed. So, an increase in pest population was observed and the research was directed towards rapid pest management during which pesticides came into limelight. 
In modern agriculture, in view of the rapid progress in newer techniques of cultivation and availability of several options of crop management practices, reliance exclusively on chemical control for insects in pest management was seen. However, it has not yielded desired returns to the farmer, as it has increased the cost of cultivation of the farmers. Indiscriminate use of pesticides by the farmers also had affected the environment polluting the soil, air and water. Its use also affected health of the farmers and also the consumers. Furthermore the quality of the crop produce is also lowered with the residues of the pesticides, decreasing the export value of the produce. Hence, reduction in the indiscriminate use of pesticides had become need of the hour in India. The farmers and also beneficial for the environment as well as the health of both farmers and consumers.

Thus, it has now became imperative to develop a holistic system of tackling pests to make it more environmental friendly, economically viable and socially acceptable for the farmers. So, since the 1980s, Integrated Pest Management (IPM) concept, IPM have been implemented in developing countries as an alternative to pesticides to reduce pesticide use. Integrated pest Management (IPM), a sound alternative to the conventional use of chemicals, has become an integral part of crop production in all the crops. It aims to keep the pest populations below the economic threshold levels through an ecologically sound, economically practical and socially acceptable technology. Host plan resistance along with natural, biological and cultural control is the backbone of the IPM system (Vantharaj David and Ramamurthy, 2016). IPM is a scientific approach based on knowledge of pest, that will reduce the pest population instead of eradication of pest.

Imparting knowledge on modern technology to the farmers has become one of the most important mandate of the extension system of India. Therefore, Krishi Vigyan Kendras which are well established and approachable extension units of extension system of India, available in almost all the districts of India are directed to organize farmers training programmes for small and marginal farmers to augment farmers income from the limited resources available with him. With the major focus on doubling of farmers income, the first initiative thought of Krishi Vigyan Kendra, Utukur, Kadapa running under the administration of Acharya N G Ranga Agricultural University was to reducing cost of cultivation of the farmers by sensitizing and training them regarding Integrated Pest Management. Initially, KVK has created awareness on IPM practices through - mass media and sensitized the farmers Interested farmers contacted KVK to know the concept of IPM and various tools and techniques used in IPM for reducing the cost of cultivation and increase their net profit. Thus, training on IPM had become one of the important flagship programme of KVK, Utukur Kadapa. Six training programmes were conducted on IPM at Krishi Vigyan Kendra, Utukur from 2015 to 2017.

About, 180 trainees were trained on the IPM concepts of the important crops grown in Kharif aand Rabi in Kadapa district. Evaluation of these training programmes is needed for the knowing its utility and effectiveness offered to the community (Astoth, 1991; Butler 1991; Johnson and Verma, 1990) and also for further improvement of the training programme. Evaluation also helps to answer the questions on accountability, effectiveness, relevance and strategies about the training programmes (Suvedi, 2011). With this objective, the present study was designed to evaluate the effectiveness of farmers trainings on IPM practices held at Krishi Vigyan Kendra, Utukur, Kadapa. 


\section{Materials and Methods}

This study was conducted at KVK, Utukur, Kadapa district of Andhra Pradesh. A sample of 30 active trainees participated in training of IPM at KVK, Utukur, Kadapa from 2015-16 to 2017-18 were selected.

Two variables namely, respondents socio economic status and their knowledge levels about the IPM practices learned in training programme at KVK Utukur were measured by a structured interview schedule to study outcome of the training.

The impact was evaluated by knowing the adoption status of IPM practices by the trainees, the problems faced by them in adoption of these practice.

For evaluating socio economic profile of trainees, 8 aspects viz., age, sex, marital status, education, family background, annual income, farming experience and mass media participation were considered.

To evaluate knowledge test, pre and post training knowledge scores of the respondents with respect to knowledge on IPM practices viz Seed treatment, intercrop, border crop, trap crop, pheromone traps, sticky traps, neem oil, Bacillus thuringiensis (Bt), income, Benefit Cost (BC) Ratio were evaluated.

To evaluate adoption status, relative position of a respondent regarding adoption, nonadoption and discontinuation with IPM practices was taken. The data regarding adoption status and problems faced in adoption was taken through telephone and personal contact.

To evaluate economic impact, the percentage increase in household income with adoption of IPM practices after participating in training was taken into considered.

\section{Statistical analysis}

Evaluation was done based on the tool developed by Kay Rockwell (1999) and followed by Nagaraj et al., 2017 and Dharminder singh and K B Singh (2016).

Socio economic profile of the respondents was evaluated using simple statistical tool viz., frequency and percentage.

Knowledge test of participants regarding different sub components of IPM practices was evaluated by conducting pre and posttest. Pretest was conducted to know how much the trainees have knowledge on various aspects of IPM practices. Similarly, after completion of training post evaluation was performed in order to assess the knowledge gained by the trainees. Pre and post evaluation test was conducted for the participants using structured questionnaire. One and zero score was assigned for the correct and incorrect responses respectively and the maximum attainable score is 20 and converted in percentage.

Overall knowledge gain of the respondents and its significance was calculated by using paired t-test.

Adoption status, problems faced in adoption of IPM practices was evaluated using simple statistical tool viz., frequency and percentage.

\section{Results and Discussion}

\section{Socio economic profile}

Out of 180 participants, a sample of 30 trainees actively participated in the training were selected, representing different mandals of Kadapa district. The distribution of respondents based on socio economic profile is given in $\mathrm{T}$ able 1. $(\mathrm{N}=30)$. From table 1, it is inferred that a typical trainee was old aged 
(> 50 years) married males. Majorly, education level of them is illiterate to primary educated, from rural and agricultural background, had a gross monthly income of less than Rs 10,000.

\section{Knowledge gain}

Different topics in the training covering seed treatment, intercrop, border crop, trap crop, pheromone traps, sticky traps, neem oil, Bt, increase in net income, $\mathrm{BC}$ ratio were explained in the training. Pre and post evaluation test was conducted for the participants by using 10 aspects of 20 structured questionS. One and zero score was assigned for the correct and incorrect responses respectively and the maximum attainable score is 20 . The gain in knowledge was reflected in terms of difference between number of trainees giving correct responses before and after the training programme. Paired t-test was applied to measure the impact of training with respect to their overall knowledge level of the trainees. The data in table 2 pertains to pre and post training mean knowledge scores of the respondents with respect to various IPM practices. The pre training mean knowledge score of various practices ranged from 0 to 3 out of 20 and that of post training mean knowledge score of various practices ranged from 14 to 19 out of 20 . It can be seen that more number of trainees was able to give correct response regarding various IPM practices after attending the training programme.

\section{Overall knowledge gain}

From table 2, the arithmetic mean of pretraining test was 1 . and increased to 17.3 after training with the variance of 1.5 and 3.12 respectively. The $t$ values of difference between pre and post training mean knowledge score of all the practices of mushroom farming were significant $(\mathrm{p}<0.01)$. Post evaluation scores of gain in overall knowledge about various practices indicate 70-95 \% improvement in their knowledge. The results showed that, prior to the training, the trainees were less aware with respect to their knowledge and understanding about the IPM aspects. But after the training, there is significant increase in the knowledge level of trainees. All the trainees had positive change in the level of knowledge after the training.

\section{Adoption status}

Adoption status of IPM was studied to know the impact of training programmes and was measured in terms of continued adopters, discontinued and non-adopters of mushroom cultivation enterprise. From the table 3 , it is indicated that 85.8 percent of the trainees had adopted IPM (52.8\% continued and $33 \%$ discontinued) where as 13.2 percent did not adopt. From Tale 4, It can be observed that various problems faced by farmers were labour work load in sowing intercrop, nonavailability of pheromone traps, nonavailability neem oil and Bt in pesticide shops, fear of increase in pest population if not sprayed of which majority fear of increase in pest population if not sprayed regularly.

Integrated pest management (IPM) is a highly effective method form an aging pest insect species (Abrol 2013).This management system enriches ecosystem processes and can provide a healthy, sustainable food source for range of organisms (Hillocks and Cooper 2012). Our findings showed similar results as that of Gautham et al., IPM training of farmers in Kadapa increased farmers' knowledge of insect pests and their positive attitudes toward IPM. The training reduced the spraying frequency and contributed to a safer handling of pesticides. However, as our findings did not confirm that IPM training increased total household income. A possible reason for the lack of impact of IPM is the limited local availability of biocontrol products (Table 4). 
Table.1 Socio economic profile of the respondents participated in the training

$$
\mathrm{N}=50
$$

\begin{tabular}{|c|c|c|c|}
\hline S No & Characteristics & Frequency & Percentage \\
\hline \multirow[t]{4}{*}{1} & Age & & \\
\hline & Young (less than 30 years) & 01 & 3.3 \\
\hline & Medium (31-50 years) & 04 & 13.2 \\
\hline & Old (more than 50 years) & 25 & 82.5 \\
\hline \multirow[t]{3}{*}{2} & Sex & & \\
\hline & Male & 28 & 92.4 \\
\hline & Female & 02 & 6.6 \\
\hline \multirow[t]{3}{*}{3} & Marital status & & \\
\hline & Married & 28 & 92.4 \\
\hline & Unmarried & 02 & 6.6 \\
\hline \multirow[t]{4}{*}{4} & Education & & \\
\hline & Illiterate and primary & 17 & 56.1 \\
\hline & Upto Matriculation & 12 & 39.6 \\
\hline & Above matriculation & 01 & 3.3 \\
\hline \multirow[t]{3}{*}{5} & Family background & & \\
\hline & Rural & 27 & 89.1 \\
\hline & Urban & 03 & 9.9 \\
\hline \multirow[t]{3}{*}{7} & Family occupation & & \\
\hline & Agriculture & 30 & 100 \\
\hline & Other & 00 & 00 \\
\hline \multirow[t]{4}{*}{8} & Annual income & & \\
\hline & Low (less than Rs 50,000) & 14 & 46.2 \\
\hline & Medium $(50,000$ to $1,00,000)$ & 10 & 33 \\
\hline & High (above Rs $1,00,000$ ) & 06 & 19.8 \\
\hline \multirow[t]{4}{*}{9} & Mass media participation & & \\
\hline & low & 02 & 6.6 \\
\hline & medium & 07 & 23.1 \\
\hline & high & 21 & 69.3 \\
\hline
\end{tabular}


Table.2 Gain in knowledge after acquiring training with respect to different aspects

\begin{tabular}{|c|c|c|c|c|}
\hline $\begin{array}{l}\text { S } \\
\text { No }\end{array}$ & Particulars & $\begin{array}{l}\text { Pre evaluation } \\
\text { Score out of } 20\end{array}$ & $\begin{array}{l}\text { Post evaluation } \\
\text { Score out of } 20\end{array}$ & $\begin{array}{l}\text { Improvement } \\
\text { in knowledge } \\
\text { Score out of } \\
20\end{array}$ \\
\hline 1 & Seed treatment (wet and dry) & $03(15)$ & $19(95)$ & $16(80)$ \\
\hline 2 & Intercrop and Border crop & $02(10)$ & $17(85)$ & $15(75)$ \\
\hline 3 & $\begin{array}{l}\text { Removing of egg masses and } \\
\text { sweeping }\end{array}$ & $01(5)$ & $18(90)$ & $17(85)$ \\
\hline 4 & Trap crop and poison bait & $00(0)$ & $19(95)$ & $19(95)$ \\
\hline 5 & Pheromone and Sticky traps & $02(10)$ & $18(90)$ & $16(80)$ \\
\hline 6 & Light traps and bird perches & $03(15)$ & $18(90)$ & $15(75)$ \\
\hline 7 & Neem oil \& NSKE & $01(5)$ & $19(95)$ & $18(90)$ \\
\hline 8 & $\mathrm{Bt}$ and NPV & $00(0)$ & $14(70)$ & $14(70)$ \\
\hline 9 & Parasites and Predators & $00(0)$ & $16(80)$ & $16(80)$ \\
\hline 10 & Gross and Net income & $00(0)$ & $15(75)$ & $15(75)$ \\
\hline \multicolumn{5}{|c|}{ Statistical Analysis } \\
\hline 1 & Mean & 1.2 & 17.3 & \\
\hline 2 & $\mathrm{~N}$ & 10 & 10 & \\
\hline 3 & Standard Deviation & 1.23 & 1.77 & \\
\hline 4 & $t$ value & \multicolumn{2}{|c|}{33.4} & \\
\hline
\end{tabular}

(\% in parenthesis and $* *$ significant at $\mathrm{p}<0.01$ with $\mathrm{df}=9$ )

Table.3 Adoption of mushroom cultivation by the trainees $(\mathrm{N}=50)$

\begin{tabular}{|l|c|c|}
\hline Category & Frequency (n) & Percentage (\%) \\
\hline Continued adopters & 16 & 52.8 \\
\hline Discontinued & 10 & 33 \\
\hline Non adopters & 04 & 13.2 \\
\hline
\end{tabular}

Table.4 Problem faced in adoption of mushroom cultivation $(n=50)$

\begin{tabular}{l} 
Problem \\
\hline labour work load in sowing intercrop, \\
\hline Non avalability of inputs vir., \\
pheromone traps, neem oil and $\mathrm{Bt}$ in \\
near by areas. \\
Fear of increase in pest population if \\
not sprayed (38\%), \\
(\% written in parenthesis)
\end{tabular}


Our intervention focused on the use of pheromone lures and traps, but these traps and lures were not widely available in rural areas of Kadapa, which may have limited farmers to practice what they had learned during the training

More generally, our results confirm the findings of reviews by Vanden Berg and Jiggins (2007) and Pretty and Bharucha (2015), which showed that IPM are effective at reducing agricultural pesticide use, though not always at increasing crop yields and profits. Farmers often become dependent on pesticides without giving consideration to the environmental consequences. Unfortunately, this is a common occurrence because there is less concern for environmental protection when food production takes precedence, as is often the case in the developing world. Integrated Pest Management (IPM) is a highly effective method for managing pest insect species. This management system enriches ecosystem process and can provide a healthy, sustainable food source. Most farmers do not understand the impact pesticide use can have on their health. This is most often due to the lack of knowledge surrounding pesticides mode of action.

It was concluded that to increase adoption of IPM strategies, it is necessary to increase farmer awareness and knowledge concerning environmental pollution that could be mitigated with the successful implementation of these techniques. It is important to improve farmer's pest management practices through examining current strategies and building upon pre existing knowledge. The indiscriminate use of chemical pesticides is widespread. Pesticide indiscriminate use exposes consumers and farm workers to substantial health risks, contributes to unsustainable farming practices and limits agricultural exports. This study showed that short-term training of farmers in IPM methods improved farmers' knowledge and attitudes in pest management, led to safer use of pesticides, and reduced the number of pesticide sprays. However, IPM training was more effective in reducing the quantity of pesticide used and in increasing crop yields and farm profits. Biocontrol products are increasingly available in the market and supplied by the private sector, but public sector investment is needed to expand IPM training to reach more farmers and to develop and test new and improved IPM methods. To enable widespread adoption it is important that researchers focus on the development of IPM methods that reduce costs and increase profits.

\section{References}

Abrol, D., Integrated Pest Management: Current Concepts and Ecological Perspective, 2013.

Astroth, K. A., 1991. Prevention education programs: Can they be effective? Journal of Extension 29(2): 38-39.

Butler S. W., 1991. Integrating evaluation into teaching. Journal of Extension 29(2): 35-36.

Dharminder Singh., and Singh, K B. 2016. Evaluation of vocational training programme on mushroom cultivation. Indian journal of Economics and Development vol 12 (2):387-392.

Hillocks R.J. and J.E. Cooper, "Integrated Pest-Management can it contribute to sustainable food production in Europe with decreased reliance on conventional pesticides?" 2012, http:// www.eucipm.org/docs/IPM-Can-itDeliver-DiscussionPaperNo1b.pdf.

Johnson, E., and Verma, S. 1990. Are extension publications readable? Journal of Extension 28(2): 35.

Nagaraj, R., P. Arunkumar, B.C. Hanumanthaswamy and Jyoti $M$. Rathod. 2017. Mushroom Production 
for Self Employment - An Impact Study. International Journal of Current Microbiology and Applied Science. 6(9): 2991-2997.

Pretty and Bharucha, 2015. Integrated pest management for sustainable intensification of agriculture in Asia and Africa Insects, 6 (1) (2015), pp. 152182

Rockwell, K., 1999. Does Extension make a difference: Measuring program outcomes. Unpublished, West Virginia University Jackson's Mill Conference Center.
Suvedi, M., 2011 Training manual on evaluating extension programs, Michigan State University. www.measextension.org/measoffers/trainingoffers/training/evaluating extension program.

Van den Berg and Jiggins, 2007, Investing in farmers-the impacts of farmer field schools in relation to integrated pest management World Dev., 35 (4) (2007), pp. 663-686.

David B. Vasantharaj and VV. Ramamurthy 2016. Elements of Economic Entomology 8th Edition. Brillion Publishing, New Delhi.

\section{How to cite this article:}

Gurram Ranjitha, Jillela Teza and Veeraiah, A. 2018. An Impact Study on Training Programme on Integrated Pest Management. Int.J.Curr.Microbiol.App.Sci. 7(11): 2342-2349. doi: https://doi.org/10.20546/ijcmas.2018.711.264 